\title{
The Influences Of Absorptive Capacity And Social Capital On Knowledge Transfer
}

\author{
Naresh Kumar, Universiti Putra Malaysia, Malaysia \\ Raduan Che Rose, Universiti Putra Malaysia, Malaysia \\ Nurul Fatiha Abdul Muien, Universiti Putra Malaysia, Malaysia
}

\begin{abstract}
This study investigated the current business practices in Japanese electrical and electronics manufacturing subsidiaries as well as the influences of both absorptive capacity and social capital on knowledge transfer within the firms' intra-MNC network in the wake of full AFTA implementation in 2018. Results showed that employees are generally satisfied with the current practices in these subsidiaries with relation to the eight dimensions being studied; learning system, training, communication, reward, promotion, compensation, trust and centrality. This study also found that absorptive capacity has definite but small relationship with knowledge transfer, while social capital bears much more substantial relationship with the former.
\end{abstract}

Keywords: Absorptive Capacity; Social Capital; Knowledge transfer, Multinational Corporation, Malaysia

\section{INTRODUCTION}

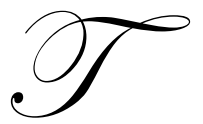

he regional integration in Southeast Asia will considerably engender inconveniences to the Japanese electrical and electronic product manufacturers. Opening up to a wider market also means attracting bigger breadth of competitors looking to reap the same benefit from the market (ASEAN, 1995). The competition is becoming more intense as the region progress closer to the year 2018, when virtually all manufacturing products would no longer be subjected to any form of trade barriers when traded within the region. Potential threat to the Japanese electrical and electronic manufacturers is the establishment of new plants from manufacturers of other nationalities in any of the ASEAN countries. This situation is even more aggravated following numerous Free Trade Agreements (FTAs) signed between ASEAN countries with other countries like China and South Korea, extending the possibilities for new manufacturers to penetrate ASEAN region. Therefore there is a need among the existing electrical and electronic manufacturers to maneuver their competitive advantage and stay relevant in the market.

On the endeavor to sustain competitive advantages, the variety of skills and knowledge embedded in any of the employees should be extracted, captured and utilized across the organization (Ordonez de Pabloz, 2004). This is even more crucial for companies operating in an industry like the electrical and electronic where creative and innovative capabilities is not unprecedented in their quest for bigger market share. Johnston and Paladino (2007) argued that subsidiaries are able to contribute in the innovation process in multinational corporations (MNCs) via two ways: 1) physically generate the product or process innovation themselves; 2) involve in knowledge and resource sharing with the rest of the MNCs. Chiang (2007) further added that subsidiary strategic independence is noticed to help elevating the MNCs overall market performance, knowledge awareness and organizational learning competitiveness. Knowledge sharing through transfer from and to every direction of the company would eventually help in facilitating higher levels of innovativeness thus supporting the company in reaching its objectives (Strach \& Everett, 2006; Chiang, 2007; Kotabe et al., 2007).

The concept of knowledge transfer within MNCs is fast to gain the interest of scholars all over the world (Napier, 2006; Strach \& Everett, 2006, Johnston \& Paladino, 2007; Miesing, Kriger \& Slough, 2007). Chiang (2007) established in his dissertation that the ability to continuously participate in learning process and to create and absorb new information is a crucial aspect in determining how the organization will fare against the competitive global 
business environment today. Lundvall and Nielsen (2007) published in their article that both opportunity and capability to access knowledge and learning-intensive networks determines the relative success of individual firms. Currently the actual knowledge transfer practice to and from every direction of a Japanese electrical and electronic manufacturing subsidiary operating in Malaysia is not generally known. Although a similar study has been conducted in 2007, its focus includes wider range of United States MNC subsidiaries operating in technologyintensive industry across Asia (Chiang, 2007). Furthermore, to the knowledge of the researchers, no similar study focusing on Japanese electrical and electronic manufacturing subsidiaries has been conducted in Malaysia. The purpose of this study is to investigate the practice of knowledge transfer intra-MNC through the subsidiaries perspectives. The study also looks into each component of absorptive capacity and social capital and how it influences the knowledge transfer practices within these companies. The following subsections briefly highlights the variables employed in this study.

\section{ABSORPTIVE CAPACITY}

In the world where competition is becoming tougher, companies must strive to learn and to develop dynamic capabilities that are difficult to replicate faster than their rivals. These capabilities are embedded in company's routines and processes and allow them to adapt quickly to ever changing and challenging surrounding business environment. Absorptive capacity is one of the most crucial dynamic capabilities for companies to achieve an edge over their competitors in terms of profitability and growth (Fosfuri \& Tribo, 2008; Zahra \& Hayton, 2008). Since absorptive capacity is a source of competitive advantage, companies which are endowed with greater absorptive capacity are generally expected to outperform its rivals (Chiang, 2007, Fosfuri \& Tribo, 2008).

The term "absorptive capacity" usually refers to the concept where an organization requires some effort, expertise or purposeful action to identify, to assimilate and to exploit any knowledge external to its boundaries (Cohen \& Levinthal, 1989). While Cohen and Levinthal (1989) considered absorptive capacity may be a barrier to knowledge transfer, Chiang (2007) argued that increasing all components of absorptive capacity will in turn increase the employees motivation and their abilities to "identify and transfer relevant knowledge from external sources" (p.23). The components of absorptive capacity include learning system, training, communication, reward, promotion and compensation (Chiang, 2007; Johnston \& Paladino, 2007). All of these six different components of absorptive capacity relate to employee motivation and ability.

Learning provides companies an opportunity to acquire and exploit knowledge internal and external of its network and allow them to immediately react to the ever changing market faster than their competitors. An entity within an MNC network may learn from its parent, peer subsidiaries, clients, suppliers, business partners as well as its competitors. Any organization undergoes both individual and organizational learning although both are different in their sequence. Individual learning occurs when any employees of the MNC acquires a new knowledge and embed it into his and the organizational memory. Organizational learning, however, is described as conscious efforts by business entities to improve their actions by acknowledging and exploiting its knowledge. Both type of learning can occur through passive and active learning.

Training based on educational background and required job-related skills relates to employees ability and motivation. Through training, employees are expected to be able to access and obtain more knowledge from diverse sources, to assess the validity of this knowledge, and to be able to assimilate the use of the knowledge according to the company's strategy (Chiang, 2007). The more relevant the available knowledge is to the employees and to the organization, the more efficient and competitive the business entity turn out to be. Communication, reward, promotion and compensation relate to the typical motivating factors used my management across the globe that could either foster or hinder performance within an MNC network. Motivation is an intentional process that provides for a certain needs or expectations that would subsequently activate desired behavior. These factor aims to provide continued satisfaction on the safety, physiological and organizational (Chiang, 2007).

\section{SOCIAL CAPITAL}

Social capital is the basis for identifying the capability of an organization to establish a relationship that would facilitate the development of knowledge sharing by promoting cooperative behavior (Chiang, 2007). Social 
capital determines how an organization link with other organizations in terms of mutual acquaintance and recognition, and has been used in connection with the context of external and internal relationships of an MNC. The main view of this concept on its application to any transnational organization is that the greater the degree of social capital developed between both MNC parent and subsidiary, the greater the degree of knowledge transfer between them (Gooderham, 2007). Two major components of social capital are trust (Ordonez de Pabloz, 2006) and centrality (Li \& Scullion, 2006).

Trust determines the extent an individual is willing to associate with and to interact with each other. This brings the individual into the organizational level of social capital apart from being the source of motivation for the individual to form relationship with one another. Similar to the concept of a subsidiary and headquarter or the peer subsidiaries, trust leads to identity and shared understanding between the two units and determine the attitude towards knowledge sharing (Chiang, 2007). Therefore, trust plays an important role in knowledge transfer and knowledge sharing between entities in any MNC network. Centrality or embeddedness, however, measures the extent of an entity within the MNC networks involvement and its importance in the search and transfer of knowledge and innovation. Role of subsidiary varies greatly from being an integrated player within the MNC network, to being the global innovator, and being the implementer (Ambos, Ambos \& Schlegelmilch, 2006). Subsidiary development and behavior is related to the level of importance it perceives itself within the MNC network, which in turns affecting the ability of the MNC to control and to integrate it into its global strategies (Chiang, 2007).

\section{KNOWLEDGE TRANSFER}

In transnational companies, knowledge transfer among affiliates and among subsidiary companies is gaining importance (Ordonez de Pabloz, 2004). A subsidiary can affect the entire MNC operations through two ways. First, the geographically dispersed subsidiary is by itself a separate organization within the MNC network which has its own distinct environmental contact through its local operations compared to the business environment surrounding the headquarter office or its peer subsidiaries. This provides the subsidiary an opportunity to absorb new, unique and useful knowledge from its environment and to contribute to the large body of knowledge within the MNC (Chiang, 2007). Secondly, the subsidiary handles the integration of knowledge so that all organizations within the MNC can benefit from it (Chiang, 2007). Previous study found that knowledge within MNC primarily moves from higher and more developed local knowledge bases to less developed countries (Ambos et al., 2006). Knowledge transfer is described as the process of moving or exchanging information from one unit to another, whether internally or externally. Knowledge transfer and knowledge sharing within an MNC occurs at three levels; sharing between parent and subsidiaries, sharing among subsidiaries and sharing among employees at a local subsidiary (Zhao \& Luo, 2005). Other literatures include knowledge transfer through international joint ventures, acquisition and formation of alliances as forms of knowledge transfer intra-organization (Chiang, 2007). Knowledge transfer can also be divided into knowledge inflow and outflow, which are differentiated according to the direction of knowledge transmission. From the point of view of the subsidiary, which is embedded in multiple network consisting both internal and external relationships, knowledge inflow indicates the knowledge transfer going into the subsidiary while knowledge outflow depicts the knowledge transfer originating from the subsidiary. The source and the recipient in both cases could either be the parent company or its peer subsidiaries.

\section{RESEARCH METHOD}

The primary data was obtained through a survey using self-administered questionnaire. The instrument developed by Chiang (2007) following the work of Schulz (2003) was adapted to measure the absorptive capacity; social capital and knowledge transfer between the Japanese headquarter offices and their subsidiaries in Malaysia. The survey questionnaire consists of 42 seven-point Likert-like scale questions to provide numerical data on the absorptive capacity dimensions: - learning system, training, communication channels, reward, promotion and compensation; trust and centrality (social capital) as well as to measure the perceptions of knowledge transfer among subsidiaries in their intraorganization network. The respondents were able to choose answers ranging from "1" describing "Strongly Disagree" to "7" being "Strongly Agree". From the analysis, it was identified that the Cronbach alpha of all constructs were between 0.75-0.91, exceeding Nunnally's (1978) recommended threshold of 0.7. Thus, the instrument used in this study showed a good level in terms of reliability. 
300 respondents were conveniently sampled from 15 Japanese subsidiaries. The subsidiaries liaison officers were given the discretion to select 20 individuals deemed suitable to participate in the survey. The entire 300 survey questionnaires were personally collected after two weeks. The returned questionnaires were then carefully screened for missing responses or unusual pattern. Only 299 or $99.67 \%$ of the survey questionnaires were used for the final analysis. The remaining 1 questionnaire was discarded due to incompletion. High response rate for this study is due to high degree of cooperation by the respondents and the subsidiaries liaison officers. In addition, the drop and pick method utilized in this survey was very effective. The data were analyzed using SPSS Version 15.

\section{FINDINGS AND DISCUSSION}

\section{Perceptions On Absorptive Capacity And Social Capital}

Respondents perceptions on all elements of absorptive capacity and social capital were categorized as low, moderate and high based on the possible score range. Table 1 shows the summary of the findings. Most of the respondents (54\%) indicated that Japanese electrical and electronics subsidiaries in Malaysia provide a commendable learning system for their employees enabling them to engage in continuous learning at the workplace. Only six respondents reported low satisfaction with the current learning system at their firm. More than half of the total respondents $(53 \%)$ moderately agree on questions related to the level of expertise of their firm's training personnel, firm's awareness of employees training needs, and employees training opportunities. About 4 percent of the respondents disagree with the statements and deem low level of practice in their firm. The lowest score recorded for respondents perception on training is 6 while the highest is 21 . This finding is consistent with that of previous research that Japanese subsidiaries in Malaysia are almost unwilling to spend for employees training due to high labor turnover in the country (Lai, 2007). Japanese subsidiaries prefer to recruit employees with prior vocational training, or possess specific level of skills and education compared to investing in training and development of their employees. Similar practices were reported in Mexico, China and Vietnam (Kenney et al., 1998; Taura, 2005; Vind, 2008). This finding, however, prove a contrary to Japanese subsidiaries in Japan and United States (Morishima, 1995; Inchniowski \& Shaw, 1999).

Table 1: Perception on level of absorptive capacity and social capital practices $(n=299)$

\begin{tabular}{|c|c|c|c|c|c|}
\hline \multirow[b]{2}{*}{ Variables } & \multicolumn{3}{|c|}{ Level of Perception } & \multirow[b]{2}{*}{ Mean } & \multirow[b]{2}{*}{ SD } \\
\hline & $\begin{array}{c}\text { Low } \\
\text { n }(\%)\end{array}$ & $\begin{array}{c}\text { Moderate } \\
\text { n }(\%)\end{array}$ & $\begin{array}{l}\text { High } \\
\text { n }(\%)\end{array}$ & & \\
\hline \multicolumn{6}{|l|}{ Absorptive Capacity: } \\
\hline Learning System & $6(2.00)$ & $132(44.15)$ & $161(53.85)$ & 14.28 & 2.96 \\
\hline Training & $11(3.68)$ & $159(53.18)$ & $129(43.14)$ & 13.65 & 2.92 \\
\hline Communication & $0(0)$ & $143(47.83)$ & $156(52.17)$ & 14.62 & 2.24 \\
\hline Rewards & $2(0.67)$ & $120(40.13)$ & $177(59.20)$ & 15.02 & 2.50 \\
\hline Promotion & $1(0.33)$ & $211(70.57)$ & $87(29.10)$ & 18.13 & 2.82 \\
\hline Compensation & $0(0)$ & $58(19.40)$ & $241(80.60)$ & 16.06 & 2.30 \\
\hline \multicolumn{6}{|l|}{ Social Capital: } \\
\hline Trust & $0(0)$ & $164(54.85)$ & $135(45.15)$ & 23.29 & 5.09 \\
\hline Centrality & $1(0.33)$ & $245(81.94)$ & $53(17.73)$ & 26.05 & 4.27 \\
\hline
\end{tabular}

The findings of this study indicated that all of the respondents are typically happy about the communication practices in their firm. 52 percent strongly agree with the current approach and the remaining 48 percent perceive a moderate level of practice related to their access to communication channels, communication between superiors and subordinates, and communication between entities in the firm's intra-MNC network. It is transparent that the managers are willing to discuss and accept ideas from their subordinates. Besides, this finding shows the subsidiaries seriousness to upgrade the locally hired human resources skills to meet the new requirements of technology (MITI, 2002). Although previous studies highlighted numerous communication problems crop up between locally hired employees and Japanese managers (Teoh, Schoch \& Lee, 1998), the findings of this study 
reveals the opposite. A study done in Singapore reported minimal level of communication between managers and the subordinate and between the headquarter and the local employees from the subsidiary in Singapore, since most forms of communication often stop at top management level (Ong, Wan \& Chng, 2003). However based on this study, such condition was not observed in Malaysia. Locally-hired employees rated the subsidiaries in Malaysia are serious in fostering communication among employees and the management team as well as with the other employees within the subsidiaries network. The findings also indicate management willingness to adopt bottom-up approach in knowledge sharing rather than following only the opposite.

59 percent of the respondents strongly perceive their efforts on knowledge sharing are substantially rewarded by their employers. 40 percent generally agree that they are rewarded for sharing information with their colleagues at work. On the other hand, 81 percent of the respondents perceived high of satisfaction with their current compensation system. The remaining 19.4 percent of the respondents showed moderate level of such practices. Since higher remuneration is always the main reason behind any knowledge transfer decision among employees, Japanese firms have adopted above average remuneration packages to retain the best talent within the organization. These are also the traditional Japanese practices to instill employee loyalty to the organization and to manage high employee turnover (Lai, 2007).

About 71 percent of the respondents perceived moderate level of promotion practices in their subsidiaries. Since Japanese firms rely heavily on the transfer of Japanese managers to fill the senior level positions in their subsidiaries abroad, locally employed managers and executives often perceive an unofficial ceiling on promotion exists in their organization (Lai, Gibbons \& Schoch, 2006). This practice had been reported from various countries like Australia, Ireland and the United States. Japanese managers are also reported to seldom praise the employees and each others work thus contributing to the factor why they are perceived to be not so serious in conducting promotion-related practice by publicizing individual achievements (Swierczek, 2003). Another reason that might have contributed to the moderate level perceptions among employees towards the subsidiaries are the traditional Japanese promotional policies itself that places higher importance on employees seniority than performance in making employees career advancement decisions (Ariga, Ohkusa \& Brunello, 1999). Nevertheless, in the present day, more and more Japanese firms are beginning to adapt result-oriented, performance-based promotion schemes (Dirks et al., 2000).

About 55 percent of the respondents indicated moderate level of trust within the subsidiaries intra-MNC network, while the remainders feel strong level of trust exists between their firms, the headquarters, and the sister subsidiaries. 82 percent of the respondents agree to moderate level of centrality of the firms within their organization network. 18 percent of the respondents perceived the firms to have strong influence on the headquarters and their sister subsidiaries. In short, the findings showed that employees perceive moderate level of importance and authority with regards to the firms' positions on intra-MNC network. These situations were earlier reported by Legewie (1999) stating that there are low level of bidirectional knowledge transfer between the Japanese subsidiaries abroad with their headquarters and peer subsidiaries since the headquarter prefer to "control all activities from Japan and transfer only limited authority to national operating units" and "conduct research and development activities almost exclusively in Japan" (Lai et al., 2006, p.52). This can also be seen through the Japanese firms' practices to transfer parent company national as a mean of controlling the subsidiaries operation. Another reasons could also be used to explain why employees perceiving moderate level of trust in the firms towards their intra-organization network is that the headquarters are reported to almost always view the non-Japanese employees in their subsidiaries abroad as "Gaijin" or outsiders, and prefer to interact with their Japanese managers abroad thus raising the trust issue among locally-hired employees against their parent firm in Japan (van de Hoven, van Valkenburg \& Heng, 1994).

\section{PERCEPTION ON ABSORPTIVE CAPACITY AND SOCIAL CAPITAL}

Absorptive capacity comprises of six dimensions: learning system, training, communication, rewards, promotion, and compensation. Trust and centrality are the only two dimensions measured for social capital. Respondents' perceptions were categorized as low, medium and high based on the possible score range between 19 and 133 for absorptive capacity, and between 11 and 77 for social capital. The recorded mean for absorptive capacity is 91.95 with standard deviation of 11.84 . About 62 percent of the respondents agree to moderate level of practices to absorptive capacity. All of the remainders perceived strong level of subsidiaries commitment towards 
increasing employees both absorptive capacity through their current approaches to learning system, training, communication, reward, promotion and compensation. The mean for social capital is 49.34 with standard deviation of 7.28. About 84 percent of the respondents observe moderate level of trust exists in the firm's intra-MNC network and the firms are of moderate importance to other entities within the same network. About 16 percent feel that their subsidiaries conduct businesses in highly trusting network. These subsidiaries are also deemed to highly influence the other business entities within their MNC network in their day to day business operation decisions. Table 2 shows the statistical analysis on respondents' perception on absorptive capacity and social capital.

Table 2: Perception on Absorptive Capacity and Social Capacity (n=299)

\begin{tabular}{|c|c|c|c|c|}
\hline Level of Perception & Frequency & $\%$ & Mean & SD \\
\hline Absorptive Capacity & & & 91.95 & 11.84 \\
\hline Low $(19-56)$ & 0 & 0 & & \\
\hline Moderate ( $57-94)$ & 186 & 62.21 & & \\
\hline High $(95-133)$ & 113 & 37.79 & & \\
\hline Social Capacity & & & 49.34 & 7.28 \\
\hline Low $(11-32)$ & 1 & 0.33 & & \\
\hline Moderate $(33-54)$ & 250 & 83.61 & & \\
\hline High $(55-77)$ & 48 & 16.05 & & \\
\hline
\end{tabular}

\section{RESPONDENTS' PERCEPTION ON KNOWLEDGE TRANSFER}

Similar to the pervious analyses, the respondents' perceptions were categorized as low, medium and high based on the possible score range between 12 and 84 for knowledge transfer. The respondents (83\%) generally perceived moderate level of knowledge transfer between the subsidiaries and other entities within their organization network. $16 \%$ of the respondents agreed to high occurrences of knowledge transfer between the subsidiaries and their headquarters while the others perceived low knowledge sharing between the subsidiaries and the peers in other locations all over the world. Subsidiaries share knowledge related to technology, sales, marketing and strategy with other units within their organizational network. Table 3 depicts the statistical analyses on respondents' perceptions of knowledge transfer.

Table 3: Perception on Knowledge Transfer $(n=299)$

\begin{tabular}{lcccc}
\hline Level of Perception & Frequency & \% & Mean & SD \\
\hline Knowledge Transfer & 5 & 1.67 & 52.25 & \\
Low ( $12-35)$ & 246 & 82.27 & \\
Moderate $(36-59)$ & 48 & 16.05 & & \\
High $(60-84)$ & & & & \\
\hline
\end{tabular}

\section{PEARSON'S CORRELATION BETWEEN PERCEIVED KNOWLEDGE TRANSFER, ABSORPTIVE CAPACITY AND SOCIAL CAPITAL}

Table 4 displays the Pearson's correlation coefficients between the research variables which indicate the strength of relationship between the eight dimensions that make up absorptive capacity and social capital with respect to perceived knowledge transfer. Based on the findings, the employees perception towards the subsidiaries current business practice related to absorptive capacity are at a moderate level. Chiang (2007) previously suggested that the greater the absorptive capacity the higher the level of knowledge transfer within an organization. However, findings of this study revealed small relationship between the absorptive capacity and knowledge transfer ( $r=.345$, $p<.01)$. The dimensions within absorptive capacity with the highest correlation value relative to one another are reward $(r=.311, p<.01)$ followed by promotion $(r=.287, p<.01)$, training $(r=.263, p<.01)$ and communication 
$(r=.257, p<.01)$. The dimension with the lowest correlation to knowledge transfer is learning system $(r=.156, p<.01)$, which is contradicting to prior study that contended that promoting free flow and providing access to knowledge significantly increase absorptive capacity and subsequently knowledge transfer (Vance \& Yongsun, 2005). On the individual dimension of social capital, centrality $(r=.576, p<.01)$ possess relatively stronger relationship with knowledge transfer compared to trust $(r=.251, p<.01)$. These findings are consistent to the findings of previous study that claim the most important barrier to knowledge sharing is the perception of level of importance or the perception of being relevant to the process (Ardichvilli, Page, \& Wentling, 2003). This holds true for the case of a subsidiary receiving all the new technology from the parent company perceiving their input on the upcoming technology is not important to the headquarter. Similarly, a subsidiary in one location would perceive their strategic and marketing knowledge are irrelevant with respect to the demography, external environment and the specific role of their peer subsidiaries within their organization network. On the whole the absorptive capacity $(r=.345, p<.01)$ has low correlation value and smaller relationship with knowledge transfer compared to social capacity $(r=.513, p<.01)$.

Table 4: Pearson's Correlation between Perceived Knowledge Transfer, Absorptive and Social Capacity $(n=299)$

\begin{tabular}{lcc}
\hline Variables & $\boldsymbol{r}$ & Significance \\
\hline Knowledge Transfer & 1.000 & $.000^{*}$ \\
Absorptive Capacity & & $.000^{*}$ \\
Learning System & .345 & $.000^{*}$ \\
Training & .156 & $.000^{*}$ \\
Communication & .263 & $.000^{*}$ \\
Rewards & .257 & $.000^{*}$ \\
Promotion & .311 & $.000^{*}$ \\
Compensation & .287 & $.000^{*}$ \\
Social Capacity & .247 & $.000^{*}$ \\
Trust & .513 & $.000^{*}$ \\
Centrality & .251 & .576 \\
\end{tabular}

* Correlation is significant at the 0.01 level $(2$-tailed $)$

\section{CONCLUSION}

In the dynamic business environment today, firms must strive to stay ahead of others and continue being competitive in the industry. The Japanese electric and electronic manufacturing will be facing bigger challenge from regional manufacturers with the full implementation of AFTA in the year 2018. One possible way to enhance or to realize any organizations competitive advantage is by utilizing the brains within itself through the practice of knowledge transfer since the source may lie in the variety of skills and knowledge embedded in any of their employee. This practice could benefit the firm through higher level of innovativeness and advanced production capacity. Knowledge transfer within the MNC network is positively related to sales revenue, market share, profitability and firm performance, thus, it is justified for managers to incorporate the idea of knowledge transfer and its related dimension into formulation of their firm's strategy. From this study, social capital seems to have higher degree of correlation with knowledge transfer thus managers should place higher importance on issues like organizational trust and centrality. This however does not mean that managers should disregard the influence of the six other dimensions on knowledge transfer. Firms are seen to have lesser degree of knowledge sharing with the peer subsidiaries. This situation can be improved through enhancing socialization practices between entities within the organizational network. Firms may try to increase the probability of knowledge transfer between these entities through promoting activities requiring the collaboration of different entities. Examples of such activities are international training program, international-based project team and through organizing intra-organization visits for these subsidiaries.

The matter of trust may also be related to culture and language. Encouraging local employees to learn Japanese culture and language is one possible strategy to handle the problem. Japanese managers are also 
encouraged to learn about the local culture and language to lessen the effect of lack of trust from both management and the locally-hired employees and promote a sense of confidence within the firm. Other option that manager could look into is creating interaction opportunity outside work-hour between Japanese national and firms employees to get to know each other. Japanese firms are known to neglect the importance of documenting their strategy on papers and communicating the plan to the entire level within the firms. The lack of understanding of the firm's strategy and each individual responsibility are often the two main contributors to lower degree of knowledge sharing among employees and between one business units to another. Managers should take the initiative to communicate to each employee regarding the firm's current strategy, their individual responsibilities and contribution towards the strategy success to reduce confusion and to increase production efficiency within the firm. These in turn will minimize the likelihood of employees perceiving their input to certain issue irrelevant or not important to be shared with the organization. Managers should also encourage knowledge sharing behavior among employees, especially those who are working for the subsidiaries. Strategic decisions should not always be made at the headquarters, and subsidiaries and the employees within the subsidiaries should play a pivotal role in every stage of strategic planning. The parent firm should make use of the various know-hows which is already employed within the organization and subsequently gain more benefit in relation to the firm's performance and competitiveness in the industry.

\section{LIMITATION OF THE STUDY}

The findings of this study, although may be able to provide some insights to the relationship between a parent company and its subsidiary, may not be use to explain the same relationship between parent company and its Malaysian affiliates as well as between a parent company of other nationalities and its subsidiary in the same industry. While focusing exclusively on the perception of the subsidiaries, this study also will not be able to explain the bilateral relationship between the parent and its subsidiaries thus not sufficient to describe the process of knowledge transfer intra-MNC as a whole. This study will not differentiate between the two forms of knowledge; tacit and explicit, or between individual and organizational learning, as well as the complexity of the information in seeking the response from study participants (Minbaeva, 2007). No weight will be attributed to external factors like language difference and culture (Li \& Sculion, 2006 and Lucas, 2006) and each organizations internal characteristic like economic condition and management practices to the knowledge transfer practices within these subsidiaries. Finally, this study assumes that the MNCs will be entirely benefited through the continuous increase in multidirectional knowledge transfer within the organization without taking into consideration of other possible consequences like the increase in management costs and the increase in employee responsibilities (Kotabe et al., 2007, p.6).

\section{REFERENCES}

1. Ambos, T. C., Ambos, B. and Schlegelmilch, B. B. (2006). Learning from foreign subsidiaries: An empirical investigation of headquarters' benefits from reverse knowledge transfers. International Business Review, 15: 294-312.

2. Ardichvilli, A., Page, V., \& Wentling, T. (2003). Motivation and barriers to participation in virtual knowledge-sharing communities of practice. Journal of Knowledge Management, 7(1): 64-77.

3. Ariga, K., Ohkusa, Y., and Brunello, G. (1999). Fast track : is it in the genes? The promotion policy of a large Japanese firm. Journal of Economic Behavior and Organization, 38: 345-402.

4. ASEAN (1995). Industry focus. Retrieved June 19, 2008, from Association of Southeast Asian Nations: http://www.aseansec.org/10129.htm

5. Chiang J. C. (2007). Subsidiary performance in MNCs : The influences of absorptive capacity and social capital on knowledge transfer. Unpublished Doctoral Dissertation, Nova Southeastern University, Ft. Lauderdale, FL.

6. Cohen, W. A. and Levinthal, D. A. (1989). Innovation and learning: The two faces of R\&D. The Economic Journal, 99: 569-596.

7. Dirks, D., Hemmert, M., Legewie, J., Meyer-Ohler, H. and Waldenberger, F. (2000). Japanese employment system in transition. International Business Review, 9: 525-553.

8. Fosfuri, A. and Tribo, J. A. (2008). Exploring the antecedents of potential absorptive capacity and its impact on innovation performance. The International Journal of Management Science, 36: 173-187. 
9. Gooderham, P. N. (2007). Enhancing knowledge transfer in multinational corporations : A dynamic capabilities driven model. Knowledge Management Research \& Practice, 5: 34-43.

10. Ichniowski, C. and Shaw, K. (1999). The effects of human resource management systems on economic performance: An international comparison of U.S. and Japanese plants. Management Science, 45(5): 704721.

11. Johnston, S. and Paladino, A. (2007). Knowledge management and involvement in innovations in MNC subsidiaries. Management International Review, 47(2): 281-302.

12. Kenney, M., Goe, W. R., Contreras, O., Romero, J. and Bustos, M. (1998). Learning factories or reproducing factories? Labor-management relations in the Japanese consumer electronics maquiladoras in Mexico. Work and Occupations, 25(3): 269-304.

13. Kotabe, M., Dunlap-Hinkler, D., Parente, R. and Mishra, H. A. (2007). Determinants of cross-national knowledge transfer and its effect on firm innovation. Journal of International Business Studies, 38: 259282.

14. Lai, W. H. (2007). The adoption of Japanese recruitment practices in Malaysia. International Journal of Manpower, 29(4): 362-378.

15. Lai, H. C., Gibbons, P. T. \& Schoch, H. P. (2006). The management of information and managers in subsidiaries of multinational corporations. British Journal of Management, 17: 153-165.

16. Legewie, J. (1999). Manufacturing strategies for Southeast Asia after the crisis : European, US and Japanese firms. Business Strategy Review, 10(4): 55-64.

17. Li, S. \& Scullion, H. (2006). Bridging the distance: Managing cross-border knowledge holders. Asia Pacific Journal of Management, 23: 71-92.

18. Lundvall, B. A. and Nielsen, P. (2007). Knowledge management and innovation performance. International Journal of Manpower, 28(3/4): 207-223.

19. Meising, P., Kriger, M. P. and Slough, N. (2007). Towards a model of effective knowledge transfer within transnational : The case of Chinese foreign invested enterprises. Journal of Technology Transfer, 32: 109122.

20. Minbaeva, D. B. (2007). Knowledge transfer in Multinational Corporations. Management International Review, 47(4): 567-593.

21. MITI, Ministry of International Trade and Industry (2002). Minister's Speech at $23^{\text {rd }}$ Joint Conference of MAJECA-JAMECA, Cyberview Lodge Resort, Cyberjaya, Monday 4 March 2002, 1.00 pm. Retrieved on October 20, 2008, from Ministry of International Trade and Industry: http://www.miti.gov.my

22. Morishima, M. (1995). Embedding HRM in a social context. British Journal of Industrial Relations, 33(4): 617-40.

23. Napier, N. K. (2006). Cross cultural learning and the role of reverse knowledge flows in Vietnam. International Journal of Cross Cultural Management, 6(1): 57-74.

24. Nunnally, J. (1978). Psychometric theory. New York: McGraw-Hill.

25. Ong, C., Wan, D. \& Chng, S. (2003). Factors affecting individual innovation: an examination within a Japanese subsidiary in Singapore. Technovation, 23: 617-631.

26. Ordonez de Pabloz, P. (2004). Knowledge flow transfers in multinational corporations: Knowledge properties and implications for management. Journal of Knowledge Management, 8(6): 105-116.

27. Ordonez de Pabloz, P. (2006). Transnational corporations and strategic challenges : An analysis of knowledge flows and competitive advantage. The Learning Organization, 13(6): 544-559.

28. Schultz, M. (2003). Pathways of relevance: exploring inflows of knowledge into subunits of multinational corporation. Organizational Science, 14(4): 440-459.

29. Strach, P. and Everett, A. M. (2006). Knowledge transfer within Japanese Multinationals: Building a theory. Journal of Knowledge Management,10(1): 55- 68.

30. Swierczek, F. W. (2003). Culture and conflict; Japanese managers and Thai subordinates. Personnel Review, 32(2): 187-210.

31. Taura, R. (2005). Japanese companies HRM strategies in China. Nomura Research Institute Paper, 86: 111.

32. Teoh, H. Y., Schoch, H and Lee, M. H. (1998). Control Systems in Multinational Companies: A MultiCase Analysis from an Organisational Context Perspective, The International Journal of Business Studies, 6(1): 82-96. 
33. Vance, C. M and Yongsun, P. (2005). Forms of host country national learning for enhanced MNC absorptive capacity. Journal of Managerial Psychology, 20(7): 590-606.

34. van de Hoven, P. T., van Valkenburg, F. P. A. and Heng, S. H. (1994). Managing information systems within Japanese companies in Europe: An empirical study. Information \& Management, 27: 315-325.

35. Vind, I. (2008). Transnational companies as a source of skill upgrading : The electronics industry in Ho Chi Minh City. Geoforum, 49: 1480-1493.

36. Zahra, S. A. and Hayton, J. C. (2008). The effect of international venturing on firm performance : The moderating influence of absorptive capacity. Journal of Business Venturing, 23: 195-220.

37. Zhao H. and Luo Y. (2005). Antecedents of knowledge sharing with peer subsidiaries in other countries : A perspective from subsidiary managers in a foreign emerging market. Management International Review, 45(1): 71-93.

\section{NOTES}

